九州大学学術情報リポジトリ

Kyushu University Institutional Repository

Canopy Structure of Mungbean Component in Maize-mungbean Intercroppings Estimated by the Stereo-image Analysis Method

Haraguchi, Tomokazu

Institute of Tropical Agriculture, Kyushu University

Hirota, 0samu

Institute of Tropical Agriculture, Kyushu University

Ahmed, Faruque

Bangladesh Agricultural Research Institute

https://doi.org/10.5109/24438

出版情報: 九州大学大学院農学研究院紀要. 46 (2)，pp. 257-266，2002-02-28. Kyushu University バージョン：

権利関係 : 


\title{
Canopy Structure of Mungbean Component in Maize-mungbean Intercroppings Estimated by the Stereo-image Analysis Method
}

\author{
Tomokazu HARAgUCHI*, Osamu HIROTA and Faruque AHMED**
}

Institute of Tropical Agriculture, Kyushu University, Fukuoka 812-8581, Japan

(Received October 19, 2001 and accepted November 20, 2001)

\begin{abstract}
Among the many aspects regarding to the effective use of natural resources in intercropping, the light condition in the canopy might be an important factor due to its complicated distribution of the foliage. For the clarifying the difference of the canopy structure, which could be related to radiative characteristics, the canopy geometry of mungbean component was estimated by the stereo-image analysis method (SIAM). The investigation was conducted in three cropping systems, i.e. one row mungbean intercropping between maize rows, two rows mungbean intercropping and a mungbean monoculture. First, the coordinates of four points on a leaflet, which determine the long- and short-axes of it, were measured by the analysis of stereo images taken by two digital cameras. Then the coordinates were used to calculate an area of a leaflet and to estimate the azimuth angle and zenith angle of it. Eventually the characteristic of foliage geometry in intercropping system was described by illustrating the spatial distributions of the leaf area, the azimuth angle and the zenith angle. The leaf area and its vertical distribution obtained by the SIAM were so fitted with those measured by the clipping method. These results showed that the SIAM might be applicable to investigate the canopy structure.
\end{abstract}

\section{INTRODUCTION}

Suitable agricultural land is fixed or rather diminishing all over the world. Recent demographic pressure has forced farmers and agricultural scientists to produce much more food from the limited cultivated land especially in developing countries. The intercropping is considered as one way of raising productivity because of maximum utilization of land and the effective use of natural and artificial resources (Midmore, 1993).

Among the many aspects regarding to the effective use of natural resources in intercropping, the light condition in the canopy might be an important factor due to its complicated distribution of the foliage. Considering the high correlation between crop growth and intercepted solar energy, the contribution of the micro-meteorological condition into crop growth would depend mainly on solar radiative environment.

The solar radiative environment in canopy is formed complicatedly by interception, reflection and penetration in foliage, and the canopy structure affects these processes. The parameters such as leaf area index (LAI), fractional interception and attenuation coefficient, which indicate the whole canopy characteristics, have been used for investigating the canopy structure in an intercropping system (e.g. Harris et al., 1987, Corlett et al., 1992, Watiki et al., 1993, Ramakrishna and Ong, 1994). While Hirota et al. (1995) discussed the canopy structure spatially using the vertical distribution of leaf area density

\footnotetext{
* Corresponding author (E-mail: thara@brs.kyushu-u.ac.jp)

** Bangladesh Agricultural Research Institute, OFRD, ARS, Pabna, Bangladesh
} 
and the relation between cumulative LAI and relative light intensity at foliage depth.

By setting the parameters related to leaf geometry, the solar radiative environment in an intercropping system could be simulated (e.g. Keating and Carberry, 1993, Ozier-Lafontaine et al., 1997). For the investigation of the detail radiative environment, the distribution of the accurate geometrical characteristics in foliage should be given. Some types of equipment such as TV cameras and 3D digitizer have been adopted to estimate the geometry of canopy (e.g. Shibayama et al., 1989, Sinoquet et al., 1991), but they are quite expensive. The purposes of this study are to introduce the system for the measuring the canopy geometry, which is composed of relative low cost components, and to evaluate its accuracy.

Although the geometry of maize component should be estimated for evaluation of the light condition in the canopy structure in the maize-mungbean intercropping, the only mungbean component is discussed in this paper as a preliminary trial.

\section{MATERIALS AND METHODS}

Two field experiments were conducted at the farm of Bangabandhu Sherik Mujibur Rahman Agricultural University, Salna, Gazipur, Bangladesh, during April 2000 to July 2000 (summer experiment) and October 2000 to January 2001 (autumn experiment). The farm is located at latitude $22^{\circ} 48^{\prime} \mathrm{N}$ and longitude $90^{\circ} 18^{\prime} \mathrm{E}$. Mungbean (Kanti) was planted in three patterns, which were 1-row intercropping with maize (Barnali), 2-rows intercropping with maize and a monocrop. Each treatment consisted of three replications, and their plots were laid out at random. The unit plot size was $5.25 \mathrm{~m} \times 4.8 \mathrm{~m}$. Seeding space was $0.3 \mathrm{~m} \times 0.1 \mathrm{~m}$ in a monocrop, and that of maize in intercroppings was $0.75 \mathrm{~m} \times 0.3 \mathrm{~m}$ (Fig. 1). In intercropping plots, mungbean were sown as 1 -row and 2-rows systems with $0.1 \mathrm{~m}$ intervals of plant to plant. A mungbean row was placed in the middle of two maize rows for 1-row system, and two mungbean rows were placed in $0.25 \mathrm{~m}$ of inter-row distance between maize rows for 2-row system. Sowing date were April 12 and October 9 in the summer experiment and autumn experiment, respectively.

The investigation of canopy structure was conducted at May 15 and 30, which were 33 and 48 days after sowing (DAS), respectively, for the summer experiment, and done at November 6 and 19, which were 28 and 41 DAS, respectively, for the autumn experiment.

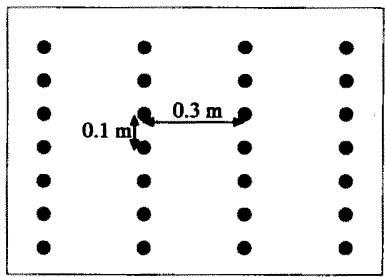

a) Mungbean monocrop

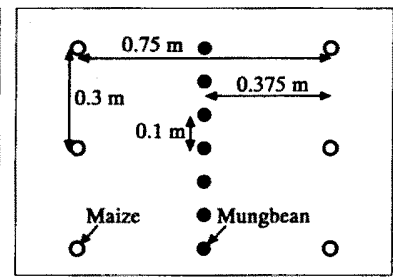

b) One row mungbean intercropping

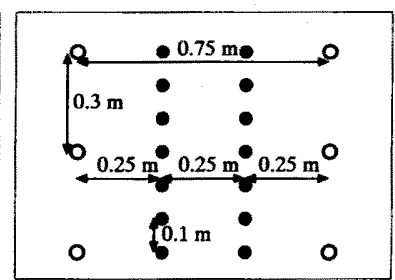

c) Two rows mungbean intercropping

Fig. 1. Diagram of planting patterns for maize-mungbean intercroppings and a mungbean monocrop. 
The measurement of foliage geometry was done for a target area, which was $0.75 \mathrm{~m} \times$ $1.0 \mathrm{~m}$ for intercroppings and was $1.0 \mathrm{~m} \times 1.0 \mathrm{~m}$ for monocrop, after maize was cut off within the area. First, the stereo-image photography of mungbean foliage using two digital cameras was conducted in accordance with the technique shown in Haraguchi et al. (2001). The leaves, on which signs were marked with paint, in a layer of canopy were photographed. Then they were cut off, and those in next layer were done. The series of the procedure was repeated from top to bottom of canopy. The repetition varied from three to nine times depending on experimental season and treatment. Second, the spatial coordinates of four points on a leaflet, i.e. two points on both edges, base and tip, were calculated by the stereo-image analysis method (hereafter as SIAM) described by Haraguchi et al. (2001). Finally, the area of a leaflet and the zenith and azimuth angle of leaf normal were estimated.

For the accuracy test of the SIAM, the leaf area was measured by the sampling method at 27 and 39 DAS in the autumn experiment and compared with the SIAM data. The leaf area by sampling method was measured using an automatic area meter (AAM-7, Hayashi Denkou Co. Ltd. Tokyo, Japan).

The area of a leaflet and the zenith and azimuth angle of leaf normal were calculated as follow procedures. The short- and long- axes of a leaflet are determined by four points on a leaflet, $l, r, b$ and $t, i . e$. left and right side and base and tip of it, respectively, as shown in Fig. 2. As far as a leaflet is flat, the leaflet area could be calculated from the lengths of the short- and long-axes of it with the technique described by Hirota and Nakano (2000). But it was difficult to determine an actual leaflet area directly by the SIAM, because almost leaflets were not flat in field condition. Hence the dummy leaflet area was used for the estimation of the leaf area distribution. The dummy leaflet area was calculated as follows. Let the points on the segment $l r$ and $b t$ at which the distance between these segments would be minimum be point $E$ and $F$, respectively. Then let the midpoint of the segment $E F$ be point $P$. The detail operations for the coordinates of

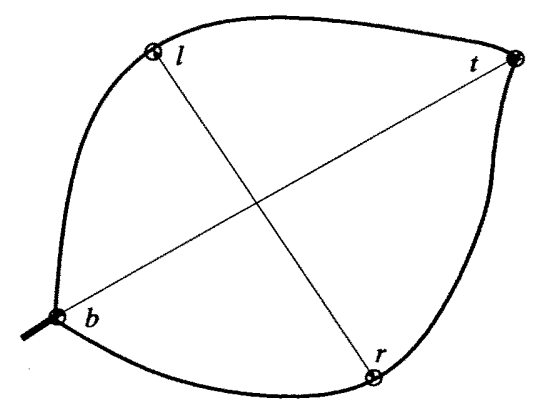

Fig. 2. Points determining the short- and longaxes of a leaflet. The marks of $l, r, b$ and $t$ denote the points of left and right side and base and tip of a leaflet, respectively. 


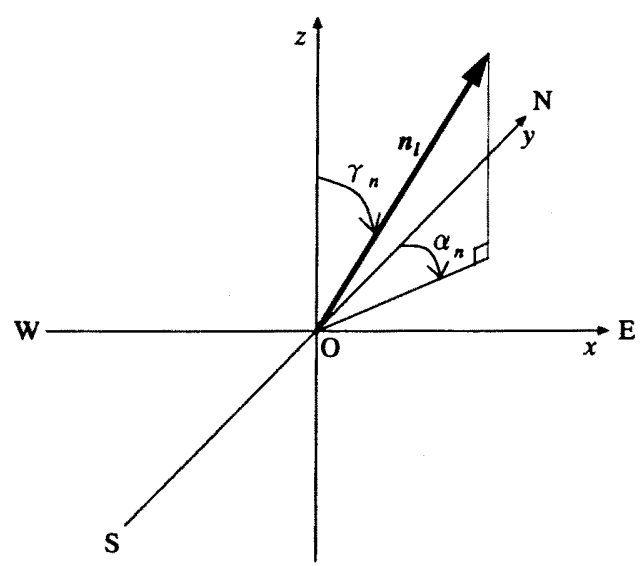

Fig. 3. Zenith angle $\left(\gamma_{n}\right)$ and azimuth angle $\left(\alpha_{n}\right)$ of a leaf normal vector $\left(n_{i}\right)$.

points $E, F$ and $P$ is shown in Appendix A. A dummy leaf area was calculated as an area of an ellipse, of which the length of axes of symmetry were $\overline{l P}+\overline{P r}$ and $\overline{b P}+\overline{P t}$.

Because a leaflet was rarely flat in natural condition, the four points on leaflet would not exist on a same plane. Hence the normal vector of a leaflet might change at every point on it. Then the representative normal vector of a leaflet was estimated as follows. The four triangles were considered on a leaflet. The triangles 1,2,3 and 4 were made up with points $l, t$ and $b$, points $r, b$ and $t$, points $b, l$ and $r$ and points $t, r$ and $l$, respectively. Let the normal vectors of them be $\boldsymbol{n}_{\boldsymbol{u}}, \boldsymbol{n}_{\boldsymbol{l}}, \boldsymbol{n}_{\boldsymbol{l}}$ and $\boldsymbol{n}_{\mathbf{l}}$, respectively. The representative normal vector, $\boldsymbol{n}_{l}\left(x_{n}, y_{n}, z_{n}\right)$, was calculated as

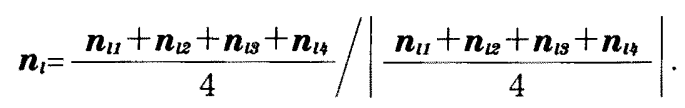

The zenith and azimuth angle of a normal of a leaflet, $\gamma_{n}$ and $\alpha_{n}$, were calculated as

$$
\gamma_{n}=\arccos \left(z_{n}\right)
$$

and

$$
\alpha_{n}=\left\{\begin{array}{ll}
\arccos \left(y_{n} / \sin \gamma_{n}\right) & \left(x_{n} \geq 0\right) \\
2 \pi-\arccos \left(y_{n} / \sin \gamma_{n}\right) & \left(x_{n}<0\right)
\end{array} .\right.
$$

The azimuth angle was defined to be zero when a leaflet faces to north, and to be $\pi / 2$ when it faces to east (Fig. 3).

These calculations were done for all leaflets in a target area. And the spatial distributions of the leaf area density, the zenith and azimuth angle were estimated. The structural characteristics of mungbean component were clarified by the comparisons of the spatial distributions of them. 


\section{RESULTS AND DISCUSSION}

\section{Leaf area}

On the assumption that LAI by the sampling method at 27 and 39 DAS correspond to LAI by the SIAM at 28 and 41 DAS, respectively, the comparison of these LAI was shown in Fig. 4. This figure shows that there was the linear relation between LAI by SIAM and that by the sampling method. From this result it might be judged that the coordinates of the four points on a leaflet were estimated accurately.

Because a dummy leaf area was not actual area, a ratio of the total dummy leaf area in a foliage layer, which was $0.1 \mathrm{~m}$ thick, to that in whole foliage was used for the illustrating the vertical leaf area distribution. Figs. 5 show the vertical distributions of the ratio in treatments $(\mathrm{a}-\mathrm{k})$ and the distribution of a ratio of the total actual leaf area in a foliage layer to that in whole foliage measured by the stratified clip method at 39 DAS in the autumn experiment $(1-\mathrm{m})$. For the 1-row intercropping at 33DAS in the summer experiment the stereo image photography was failure. The distribution changed for experimental season and growing stage as shown in Figs. 5 a-k.

Though the target area was different for 39DAS and 41DAS in the autumn experiment, the crop height and the shape of the distribution were similar (Figs. $5 \mathrm{i}, \mathrm{j}, \mathrm{k}, \mathrm{l}, \mathrm{m}$ and $n$ ). These results might also intend that the coordinates of the points on leaves were measured accurately by the SIAM.

\section{Zenith angle of leaf normal}

Figs. 6 show the frequency distributions of the zenith angle of leaf normal in whole foliage. The apparent difference of distribution shape could not be seen in experimental

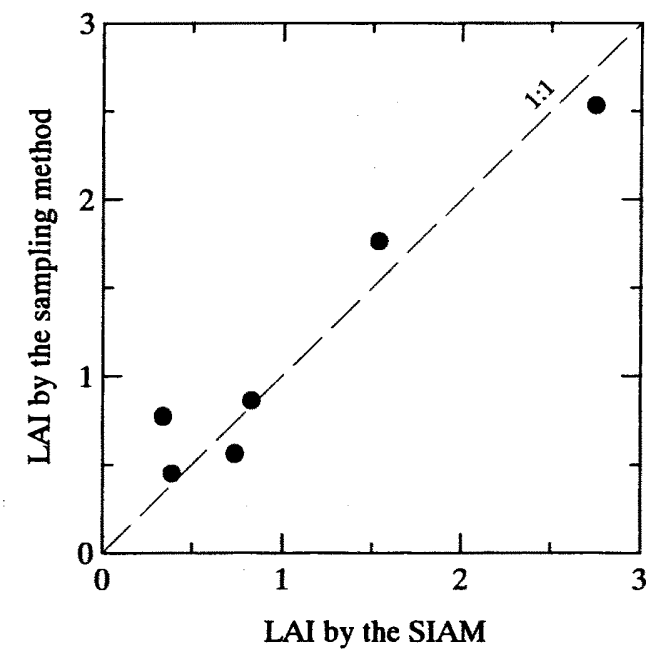

Fig. 4. Relationship between leaf area index (LAI) estimated by the stereo-image analysis method (SIAM) and that measured by the sampling method. 

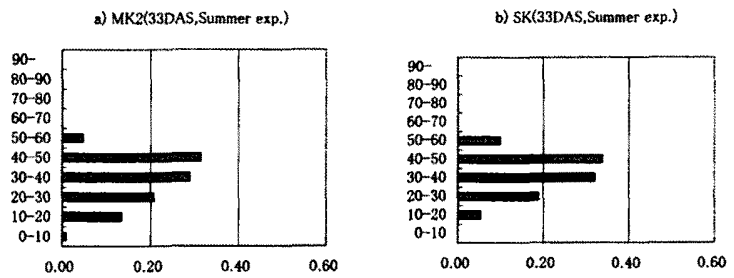

c) MK1(48DAS,Summer exp.)
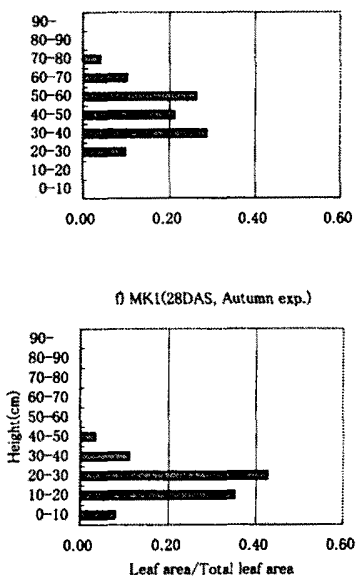

1) MKI(41DAS, Autumn exp.)

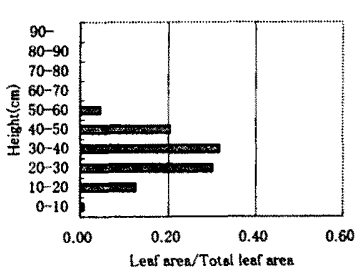

D) MKI(39DAS, Autumn exp)

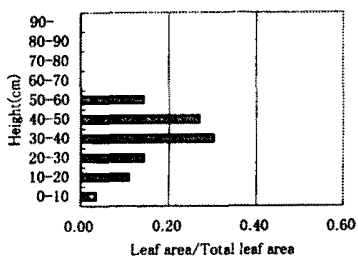

d) MK2(48DAS,Summer exp.)

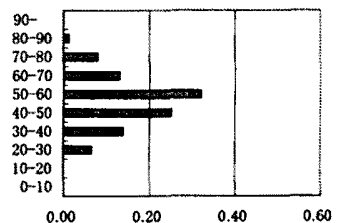

g) MK2(28DAS, Auturan exp.)

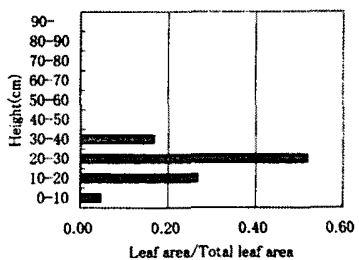

D) MK2(4IDAS, Autumn exp.)

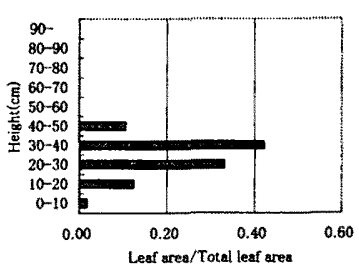

m) MK2(39DAS, Autumn exp.)

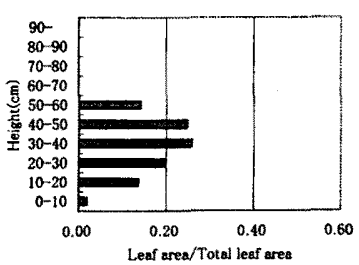

e) SK(48DAS,Summer exp.)

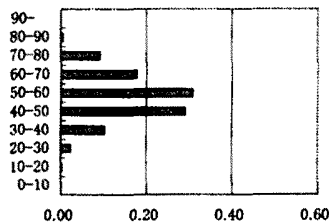

h) SK(280AS, Autumn exp.)

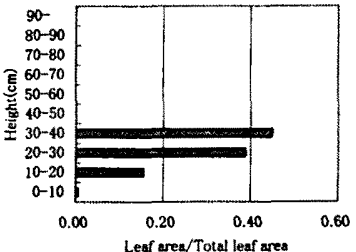

k) SK(41DAS, Autumn exp.)

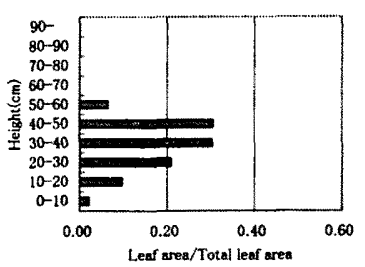

n) SK(39DAS, Autumn exp.)

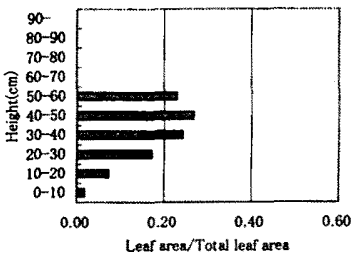

Fig. 5. Vertical distributions of the ratio of leaf area in a layer to that in whole foliage. The leaf area in figures $a-k$ is dummy leaf area, and that in figures $l-n$ is actual leaf area. MK1, MK2 and SK denote 1-row intercropping, 2-row intercropping and monoculture, respectively. 
season, growing stage and treatment except for intercropping systems at 28DAS in the autumn experiment. The average zenith angles for Figs. 6 a-k were 40.6, 35.6, 36.4, 34.5, $35.8,45.9,47.9,41.5,40.1,38.7$ and 41.5 degrees, respectively. The average zenith angle tended to decrease as the growing stage progress for intercropping.
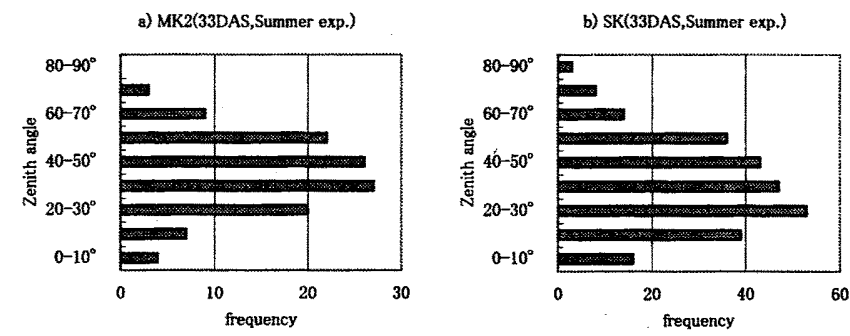

c) MK1(48DAS,Summer exp.)

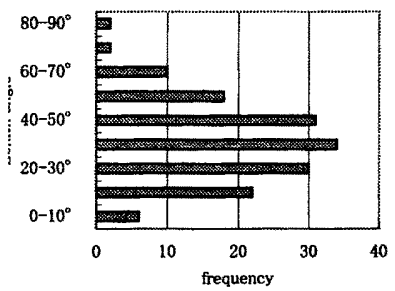

f) MK1(28DAS,Autumn exp.)

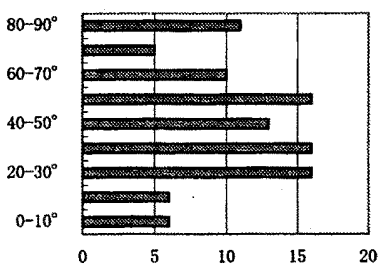

i) MK1(41DAS,Autumn exp.)

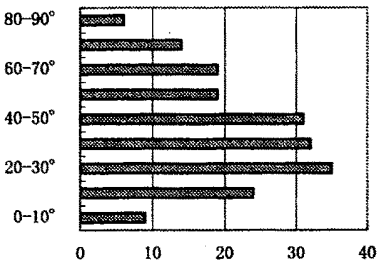

d) MK2(48DAS,Summer exp)

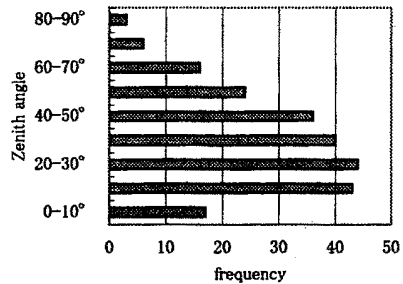

B) MK2(28DAS,Autumn exp.)

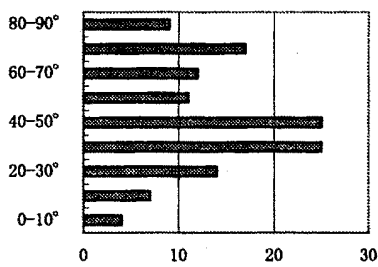

j) MK2(41DAS,Autumn exp.)

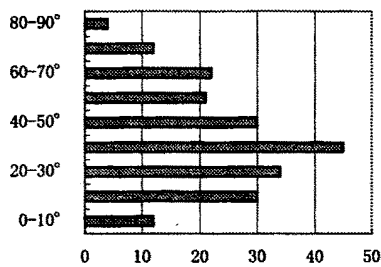

e) SK(48DAS,Summer exp.)

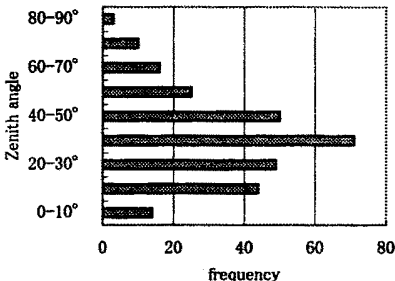

h) SK(28DAS,Autumn exp.)

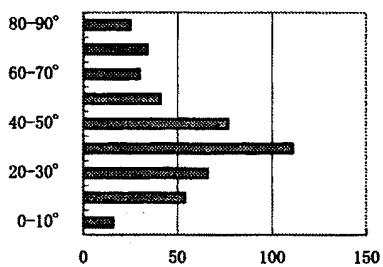

k) SK(41DAS,Autumn exp.)

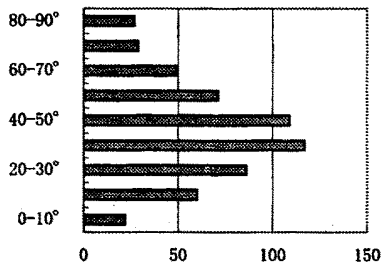

Fig. 6. Frequency distributions of zenith angle of leaf normal. MK1, MK2 and SK denote 1-row intercropping, 2-row intercropping and monoculture, respectively. 


\section{Azimuth angle of leaf normal}

Figs. 7 show the frequency distributions of the azimuth angle of leaf normal in whole foliage. The average azimuth angle was different in analysis date and treatment, but was ranged from 160 to 210 degrees, i.e. leaves were likely to face south.

The canopy geometry estimated by the SIAM was discussed only for mungbean component in maize-mungbean intercroppings in this paper. For the evaluation of the
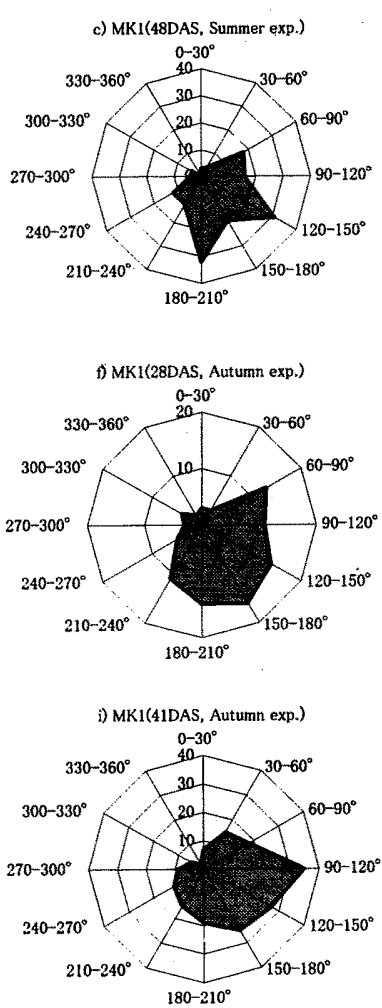
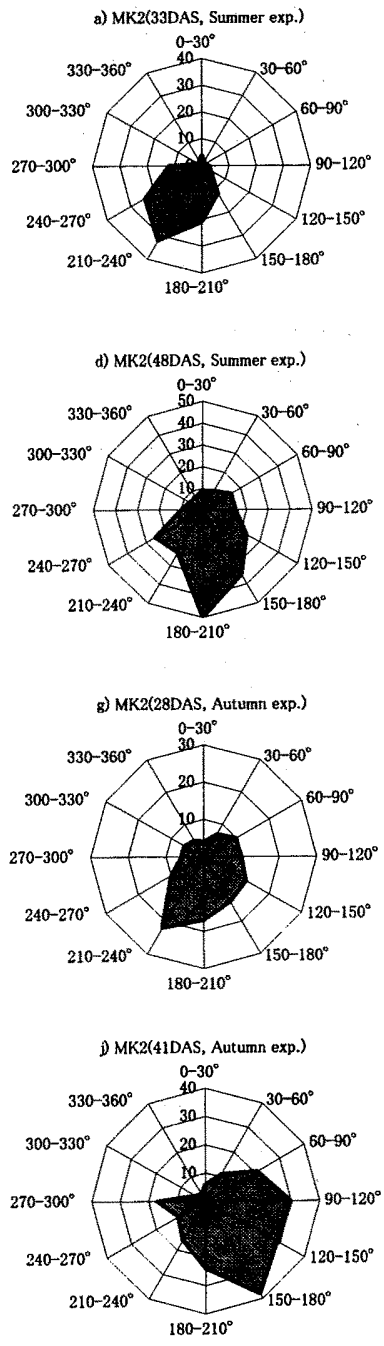
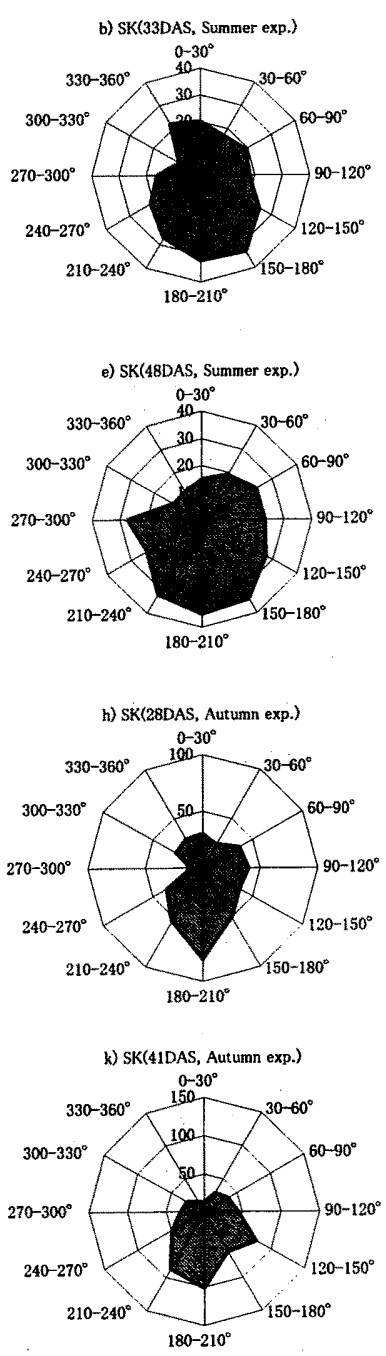

Fig. 7. Frequency distributions of azimuth angle of leaf normal. MK1, MK2 and SK denote 1-row intercropping, 2-row intercropping and monoculture, respectively. 
radiative environment in maize-mungbean intercropping systems the geometry of maize component should be estimated in a manner described in articles such as by Sinoquet et al. (1991) and by Ivanov et al. (1995). Then the whole canopy structure obtained by combining the estimated canopy structures of each component could be adopted to evaluate the solar radiation environment in the intercropping system.

\section{REFERENCES}

Corlett, J. E., C. R. Black, C. K. Ong and J. L. Monteith 1992 Above-and below-ground interactions in a leucaena/millet alley cropping system. II. Light interception and dry matter production. Agric. Forest Meteorol., 60: 73-91

Haraguchi, T., O. Hirota and F. Ahmed 2001 Development of a procedure to measure the structure of a plant community using stereo images taken by two digital cameras. Jour. Fac. Agric. Kyushu Univ., 45: $405-413$

Harris, D., M. Natarajan and R. W. Willey 1987 Physiological basis for yield advantage in a sorghum/groundnut intercrop exposed to drought. 1. dry-matter production, yield, and light interception. Field Crops Res., 17: 259-272

Hirota, O., A. Hashem and A. Hamid 1995 Yield, Photosynthesis and canopy structure of maize-mungbean intercropping system. Jap. Jour. Tropic. Agric., 39: 168-176

Hirota, O. and Y. Nakano 2000 Modeling of a soybean canopy structure by the approximation of a leaflet into an ellipsoid for estimating direct solar radiation environment. Plant Prod. Sci, 3: 67-74

Ivanov, N., P. Bissard, M. Chapron and B. Andrieu 1995 Computer stereo plotting for 3-D reconstruction of a maize canopy. Agric. Forest Meteorol., 75: 85-102

Keating, B. A. and P. S. Carberry 1993 Resource capture and use in intercropping: solar radiation. Field Crops Res., 34: 273-301

Midmore, D. J., 1993 Agronomic modification of resource use and intercrop productivity. Field Crops Res., 34: 357-380.

Ozier-Lafontaine, H., G. Vercambre and R. Tournebize 1997 Radiation and transpiration partitioning in a maize-sorghum intercrop: Test and evaluation of two models. . Field Crops Res., 49: 127-145

Ramakrishna, A. and C. K. Ong 1994 Productivity and light interception in upland rice-legume intercropping systems. Tropic. Agric., 71: 5-11

Shibayama, M., T. Akiyama, T. Watanabe and K. Munakata 1989 Three-dimensional measuring for crop canopies with TV cameras and computer-aided image processing. Bull. Green Energy Prog. Group-II (Fixation of Matter), 15: $63-86$

Sinoquet, H., B. Moulia and R. Bonhomme 1991 Estimating the three-dimensional geometry of a maize crop as an input of radiation models: comparison between three-dimensional digitizing and plant profiles. Agric. Forest Meteorol, 55 : $233-249$

Watiki, J. M., S. Fukai, J. A. Banda and B. A. Keating 1993 Radiation interception and growth of maize/cowpea intercrop as affected by maize plant density and cowpea cultivar. Field Crops Res., $\mathbf{3 5}$ : $123-133$

\section{Appendix A}

When the segment $E F$ is minimum, the vector $\overrightarrow{E F}$ is perpendicular both vectors $\overrightarrow{l r}$ and $\overrightarrow{b t}$. Hence the following equations hold,

$$
\left(x_{F}-x_{k}\right)\left(x_{r}-x_{i}\right)+\left(y_{F}-y_{E}\right)\left(y_{r}-y_{i}\right)+\left(z_{F}-z_{F}\right)\left(z_{r}-z_{i}\right)=0
$$

and

$$
\left(x_{F}-x_{k}\right)\left(x_{t}-x_{b}\right)+\left(y_{F}-y_{E}\right)\left(y_{t}-y_{b}\right)+\left(z_{F}-z_{E}\right)\left(z_{t}-z_{b}\right)=0
$$

where $x, y$ and $z$ are the coordinates and the subscripts $l, r, b, t, E$ and $F$ denote the corresponding points. Let $x_{i}-x_{j}$ be $x_{i j}$, then these equations become as 
and

$$
\left(x_{F}-x_{E}\right) x_{n}+\left(y_{F}-y_{E}\right) y_{n}+\left(z_{F}-z_{E}\right) z_{r i}=0
$$

$$
\left(x_{F}-x_{E}\right) x_{t b}+\left(y_{F}-y_{E}\right) y_{t b}+\left(z_{F}-z_{E}\right) z_{t b}=0
$$

The coordinates of points $E$ and $F$ are expressed as $\left(x_{E}, y_{E}, z_{E}\right)=\left(x_{t}+v x_{r l}, y_{l}+v y_{r l}, z_{l}+v z_{r l}\right)$ and $\left(x_{F}, y_{F}\right.$, $\left.z_{F}\right)=\left(x_{b}+w x_{t b}, y_{b}+w y_{i b}+, z_{b}+w z_{i b}\right)$, respectively, where $v$ and $w$ are parameters. Substituting these coordinates into equations (A.3) and (A.4) and solving these simultaneous equations, parameters $v$ and $w$ are obtained as,

$$
v=-\frac{b_{1} c_{2}-b_{2} c_{1}}{a_{1} b_{2}-a_{2} b_{1}}
$$

and

$$
w=-\frac{a_{1} c_{2}-a_{2} c_{1}}{a_{1} b_{2}-a_{2} b_{1}}
$$

where $\quad a_{1}=x_{n i}^{2}+y_{r t}^{2}+z_{r l}^{2}, a_{2}=b_{1}=x_{t b} x_{r i}+y_{t b} y_{r l}+z_{t t} z_{r l}, b_{2}=x_{t b}^{2}+y_{i b}^{2}+z_{t b}^{2}, c_{2}=x_{b k} x_{r i}+y_{b} y_{r i}+z_{b l} z_{r l}$ and $c_{2}=x_{b i t} x_{t b}+$ $y_{b} y_{t b}+z_{b} z_{t b}$. 